advocates intravenous Mannitol or urea, but no evidence is given to demonstrate the efficacy of these agents.

As regards local treatment, he advocates Furacin gauze followed later by sterile gauze bandages moistened hourly with Zephiran-acetic acid solution. Dressings are changed three times a day. Most Burns Units in this country would find dressing large numbers of burns three times a day difficult or impossible with the present nursing shortage. It is refreshing to see a whole chapter devoted to the nursing care of burns, and the importance of positioning the limbs and joints is stressed here together with the simple but often forgotten importance of washing of hands before and after a patient has been touched.

In a book of only 119 pages, it is not possible to mention all details of care, and some points of necessity are dealt with too briefly. Hence we find occasional dogmatic statements such as "a tracheostomy is usually performed in patients with deep neck burns". More precise indications would have been preferable. The book is written in a simple style and is interesting and easy to read. The author has succeeded in his two aims, and the book will be a useful practical guide for those without special experience in burns. Those with experience in treating burns will find much of interest, and some unorthodox ideas.

\section{Peripheal Entrapment Neuropathies}

H. P. Kopell and W. A. L. Thompson. Pp. v + 71, illustrated. Baltimore: Williams \& Wilkins, London: Baillière, Tindall \& Cox. 1963. 60s.

Of the well known mechanical neuropathies, the carpal tunnel syndrome has achieved special prominence in recent years, whilst the oddly named meralgia paræsthetica has perhaps gained historical interest out of proportion to its practical importance. This book, with its American authors and publishers, is beautifully printed and produced, and delightful to read, especially for those who gain satisfaction from relationship between structure and function.

It is concerned with the clinical features of traumatic peripheral neuropathies which may cause continuing disability, despite only moderate local injury to the hand or foot, arm or leg. In each case the anatomy is described, the mechanism of the neuropathy explained, and the symptoms and signs and treatment indicated.

The book forms a luxury addition to the well known pamphlet by the Medical Research Council on 'Aids to the Investigation of Peripheral Nerve Injuries'; published during the last war.

It will interest orthopædic surgeons. neurologists, consultants, in physical medicine and general physicians.

\section{The Retinal Ganglion Cell Layer}

J. M. Van BUREN, A.B., M.D., M.SC.. Ph.D. Pp. $143+\mathrm{x}$, illustrated. Springfield, Illinois. Charles C. Thomas. 1963. 10 dollars 75 cents.

In this work the author, who is a neuro-surgeon, describes the studies he has made in humans and primates in order to relate topagraphically the functional effects of specific lesions in the visual pathway to the anatomical changes in the ganglion cell layer of the retina. Surprisingly little previous information is available on this subject presumaby due to the difficulty, in humans, of obtaining fres ocular material from suitable patients. The authors techniques for overcoming this problem are ingeff ious and full histological data is given.

There is a tirief note of the embryology and more detailed review of the morphology of the ganglion cell layer. The author describes the varies tion in cell pattern he has observed in the normif retina of monkey, chimpanzee and human subjects. From the serial sections he is able to obtain a res constructed picture of the whole retina. He calculatess a total ganglion cell population in the human of two millions-inaccuracies may account for thes discrepancy between this figure and that usually quoted for the number of fibres in the optic nerye $(800,000-1$ million).

Retinal degeneration is described in monkeys following surgical section of the optic chiasma of tract and after occipital obligation. Detailed clinico pathological data including serial perimetry is give in eleven patients with lesions at various levels of the visial pathway ( 2 optic nerve or retina, क chiasma, 1 tract and 3 optic radition or cortexfy These lesions were either caused by tumours of injuries during hypophysectomy - not every surgeool would describe his own complications in such detali. The visual fields are superimposed upon maps of the ganglion cell population of each retina and quite close correlation was observed providing sufficient time had elapsed for degeneration occur.

This book is very well illustrated, of convenient size and can be recommended to all those interegteg in the visual pathway.

\section{Effects of Ionizing Radiation on the Nervous Syste}

A. V. LebeDINSKY and Z. N. NAKKIL'NITSKaY Pp. 211 illustrated. Amsterdam, London and New York: Elsevier. 1963. 70s.

This small translated book of 211 pages Russian authors contains, apart from the index, some 40 pages of references to the subject of isradiation of the nervous system. A large number off these references concern the work of Russian investigators who have been particularly active tin this field in recent years.

The sensory and motor pathways of the peisipheral nervous system, the autonomic nervous system, and the central nervous system and brain proper are all sensitive to varying intensities of ionizing radiation, and these aspects are separately described. The effects are assessed functionally recording alterations of conditional reflexes, by the changing responses to the action of drugs, and morphological changes. Structural alterations in the embryo, as well as the adult nerve cell, nerve fibes and synapse, are described.

Changes occurring in the cerebral vessels and circulation, in intracranial pressure, and in the prot duction of cerebro-spinal fluid are indicated, ang the disturbances of cellular nucleic acid metabolism, and trophic changes generally, are discussed. 0

This book gathers logether much of the experimental work on the physiological and pathelogical effects of ionizing radiation on nervous tissue and should prove useful to British workers engageg in the field of radio-biology, and be of interest radiotherapists. 